\title{
aeropuerto central
}

A. Alvarez, E. CARRAL, G. PEREZ olagaray, M. MARTINez PAEZ Y R. FLORES, arquitectos

$540-11$

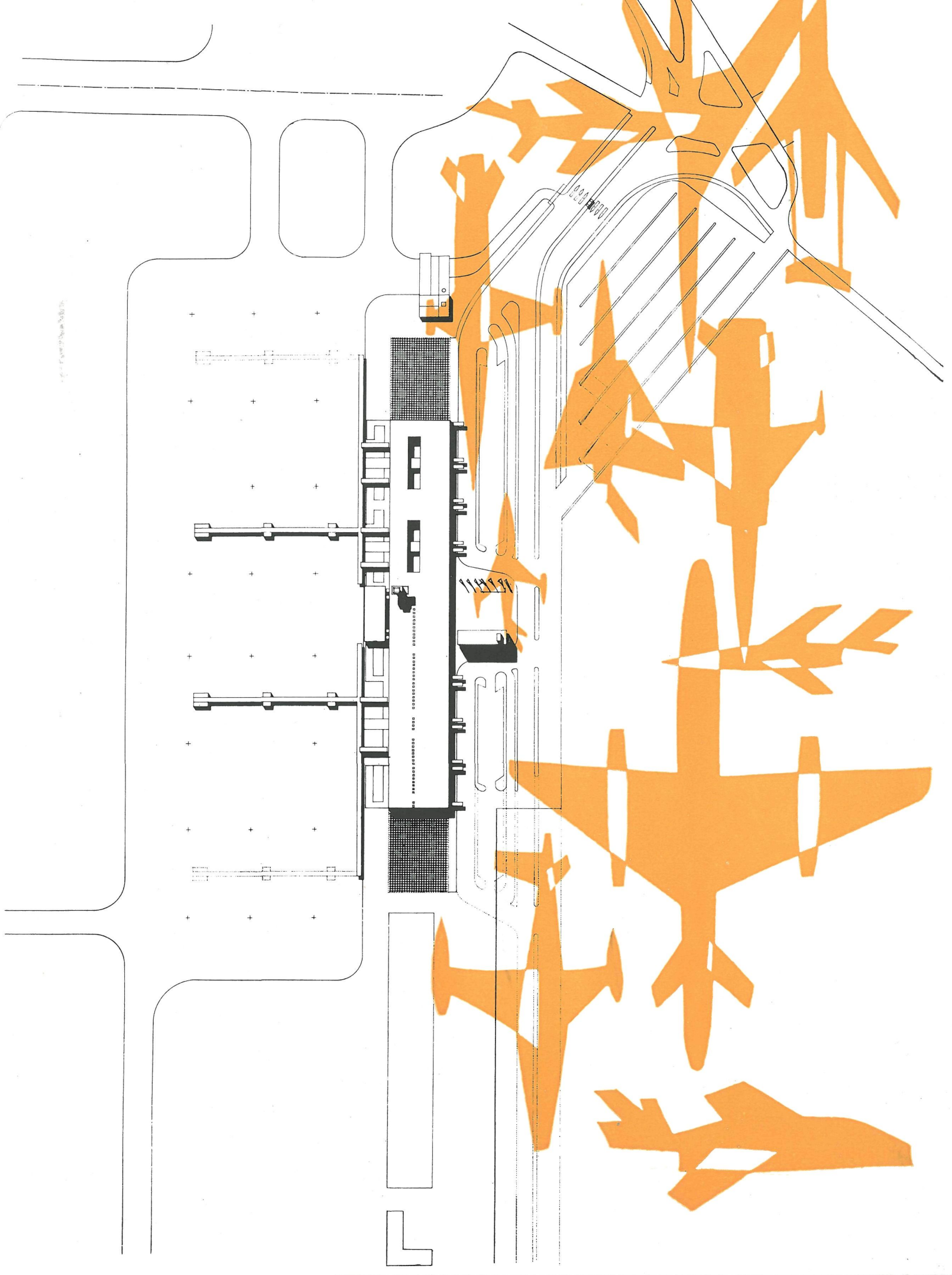


La extraordinaria importancia que ha alcanzado la aviación civil en Méjico,

y que le ha hecho ocupar el séptimo lugar entre todos los países del mundo y el primero de Hispanoamérica,

exigía un aeropuerto digno y suficiente.

Esto se ha conseguido plenamente con el Aeropuerto Central, que es hoy día, por su calidad y amplitud, uno de los primeros del mundo.

Las pistas construídas son amplias y bien pavimentadas, con capacidad de maniobra

para más de setecientos aviones diarios.

La magnitud de las obras realizadas

puede apreciarse fácilmente si se considera que,

con el volumen del hormigón que se empleó en las bases,

plantas y plataformas,

podría haberse hecho una carretera con base de $15 \mathrm{~cm}$ de espesor y $385 \mathrm{~km}$ cie larga;

y que, con el asfalto utilizado en la pavimentación

-más de diez millones de litros-

podría hacerse la pavimentación de una carretera de más de $200 \mathrm{~km}$ de longitud.

La estación terminal,

verdadero y gigantesco alarde constructivo que sorprende al viajero en su primera visita,

consta de varios cuerpos de diferente altura

sobresaliendo la estación propiamente dicha

y la dirección de aeronáutica civil.

Su capacidad de operación es de 17.280 pasajeros-día, y la superficie construída es de $19.975 \mathrm{~m}^{2}$.

El edificio principal de la estación de pasajeros tiene una longitud de $280 \mathrm{~m}$ por 42,50 de ancho,

$y$ se divide en tres partes:

el ala nacional e internacional,

con salas de espera de entrada y salida;

y la zona central, dedicada a servicios generales

- correos, telégrafos, información, cafetería,

agencia de turismo...-.

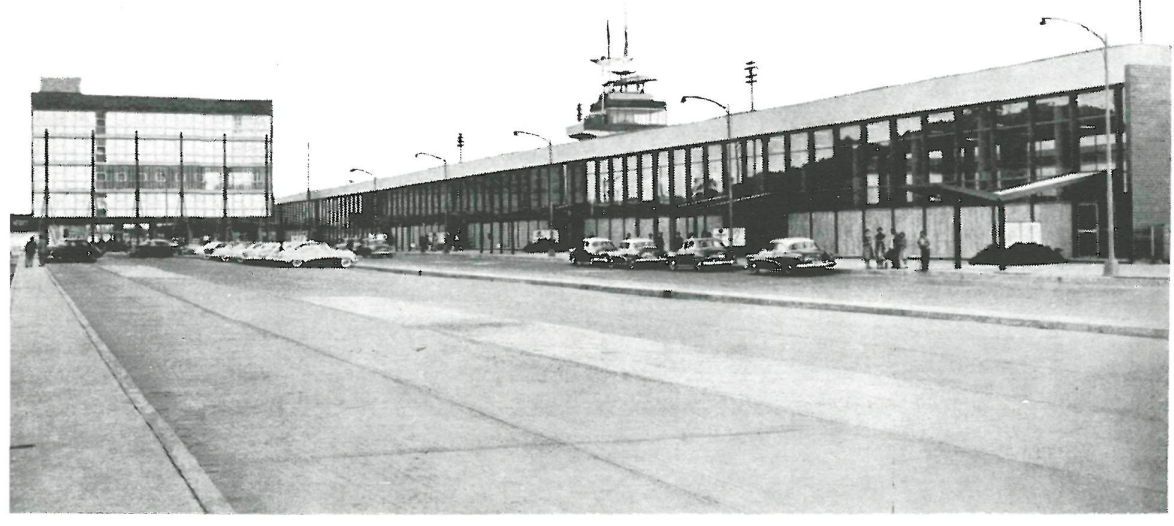




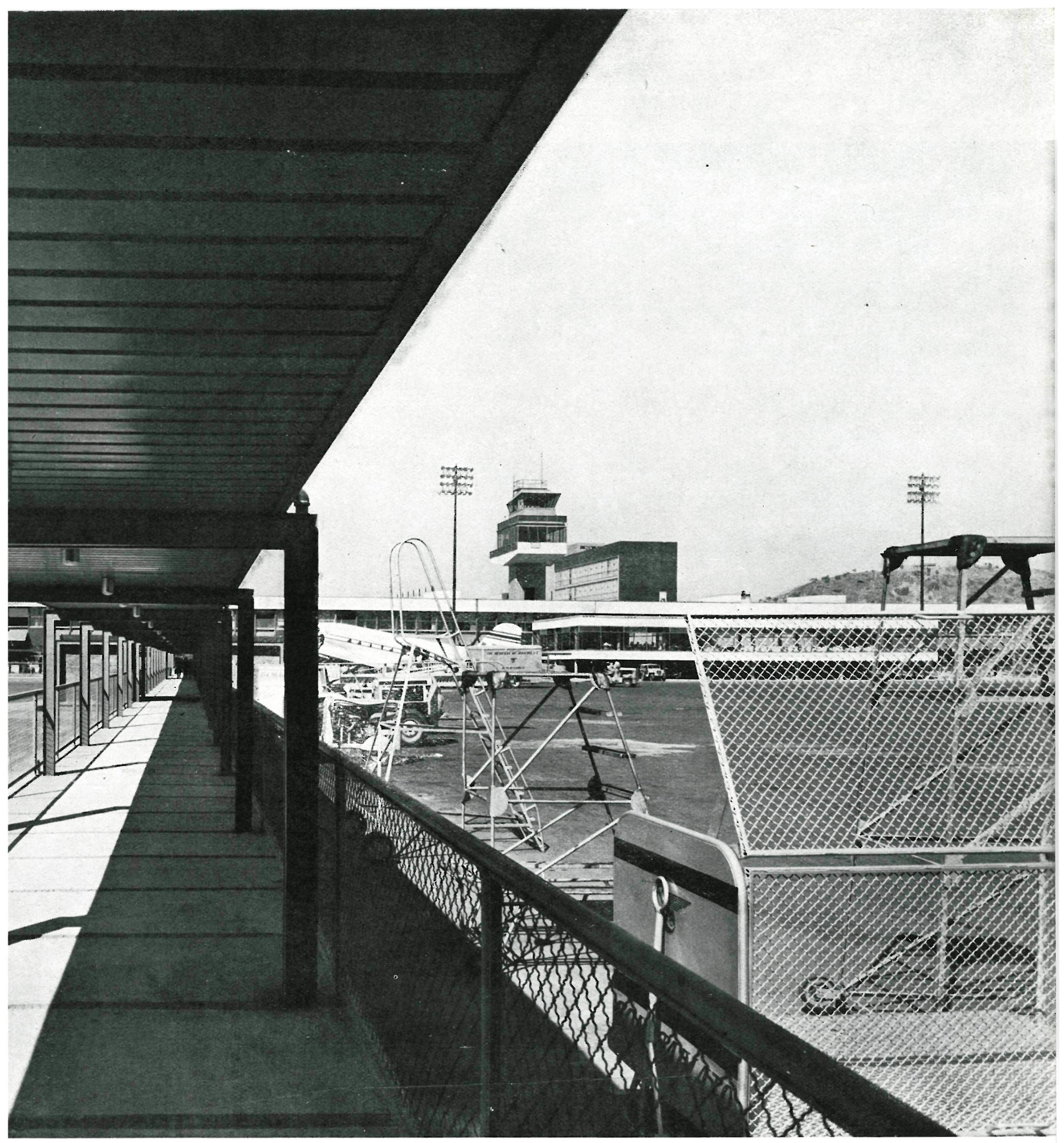

E C N I C O D E

L A

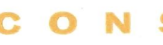

S T R U C

D E L

C E M E N T O 


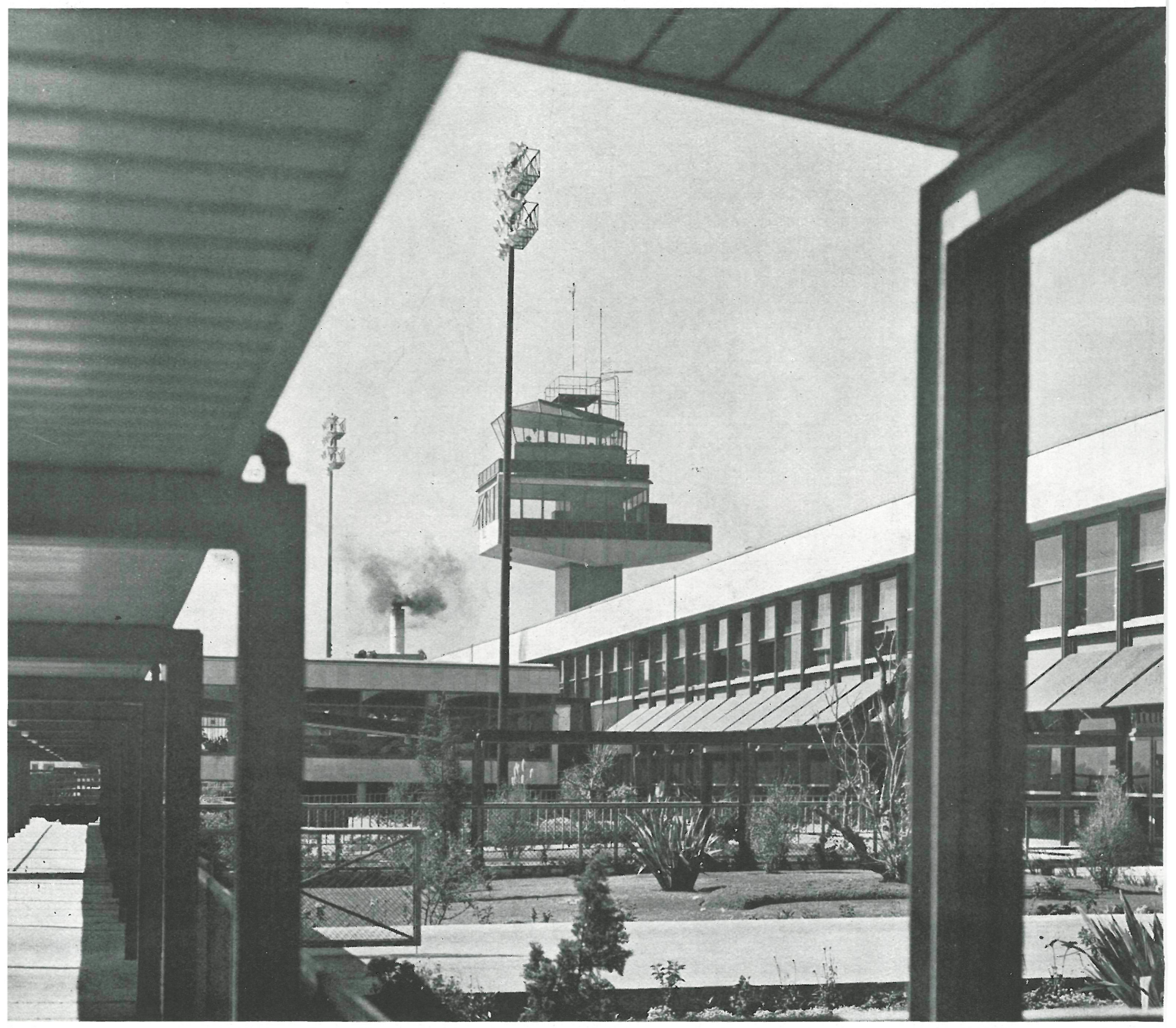

En el entresuelo se encuentran las oficinas de aduanas y de emigración, comandancia y administración del aeropuerto, torre de control, servicios meteorológicos, etc.

En este cuerpo central se distribuye también el restaurante, puestos de periódicos, teléfonos, comercios, etc., enlazados con otro cuerpo horizontal, que sobre columnas avanza sobre las pistas para crear la sala de espera, desde la que puede observarse perfectamente el tráfico aéreo. 


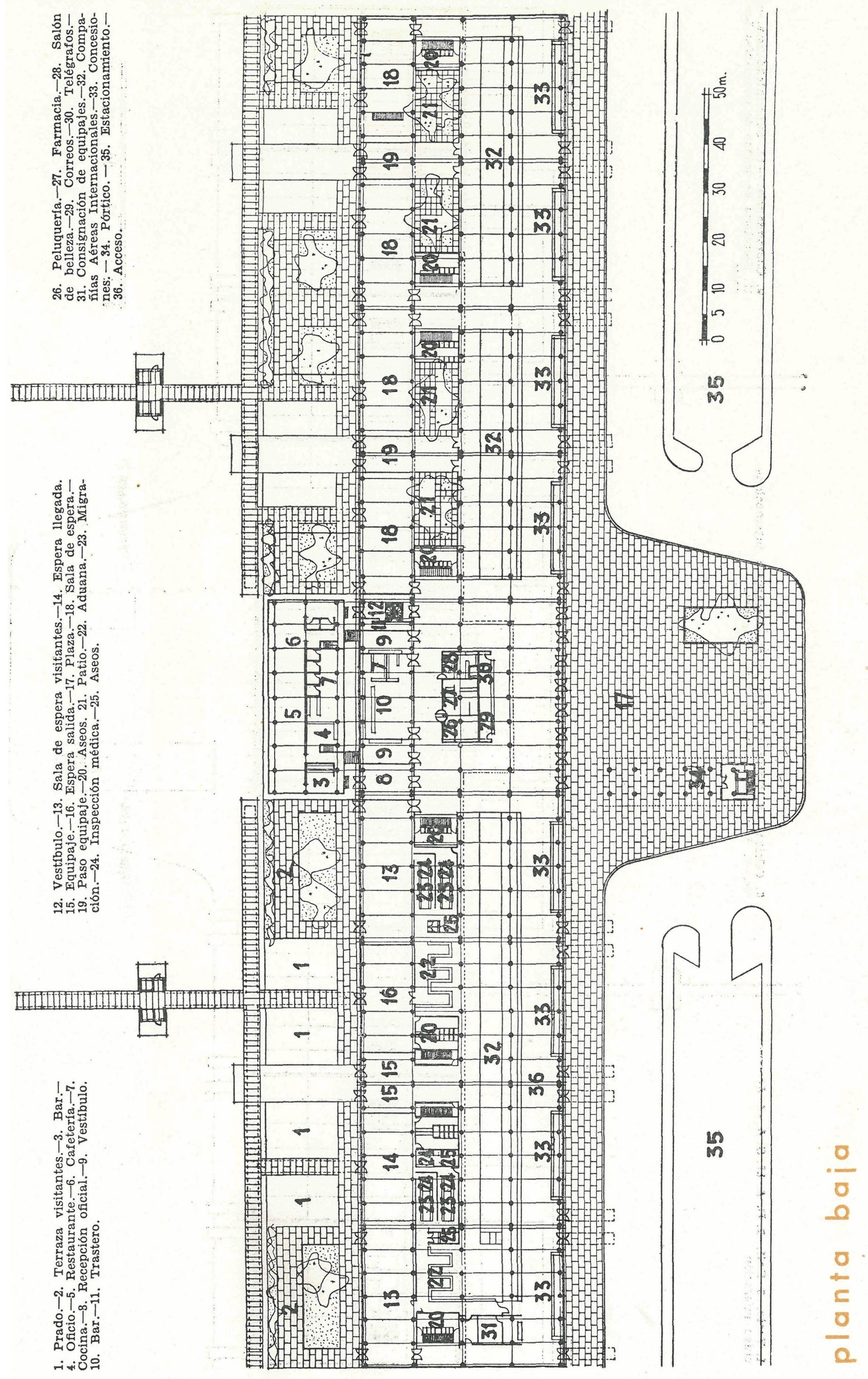




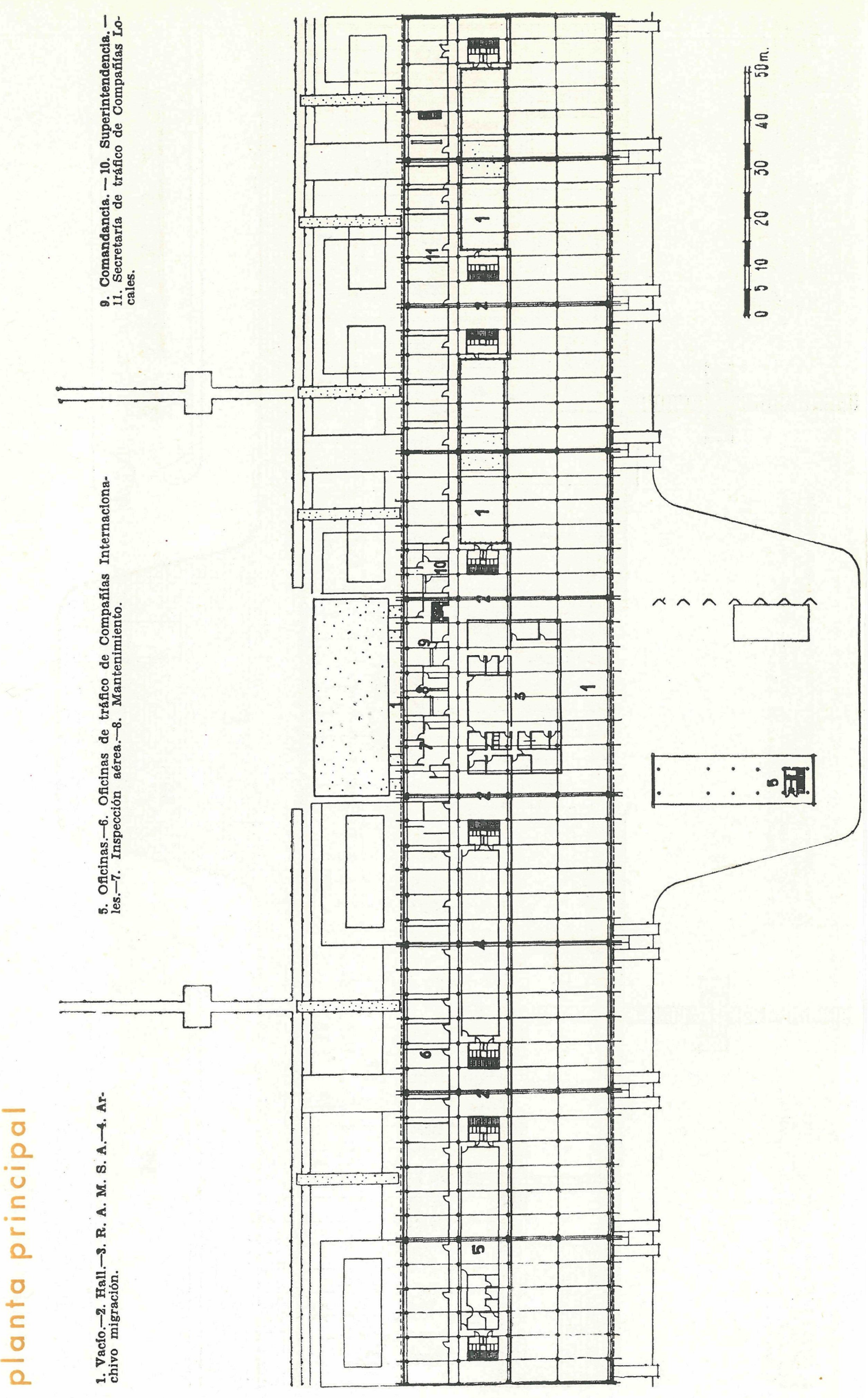




\section{sala de espera}

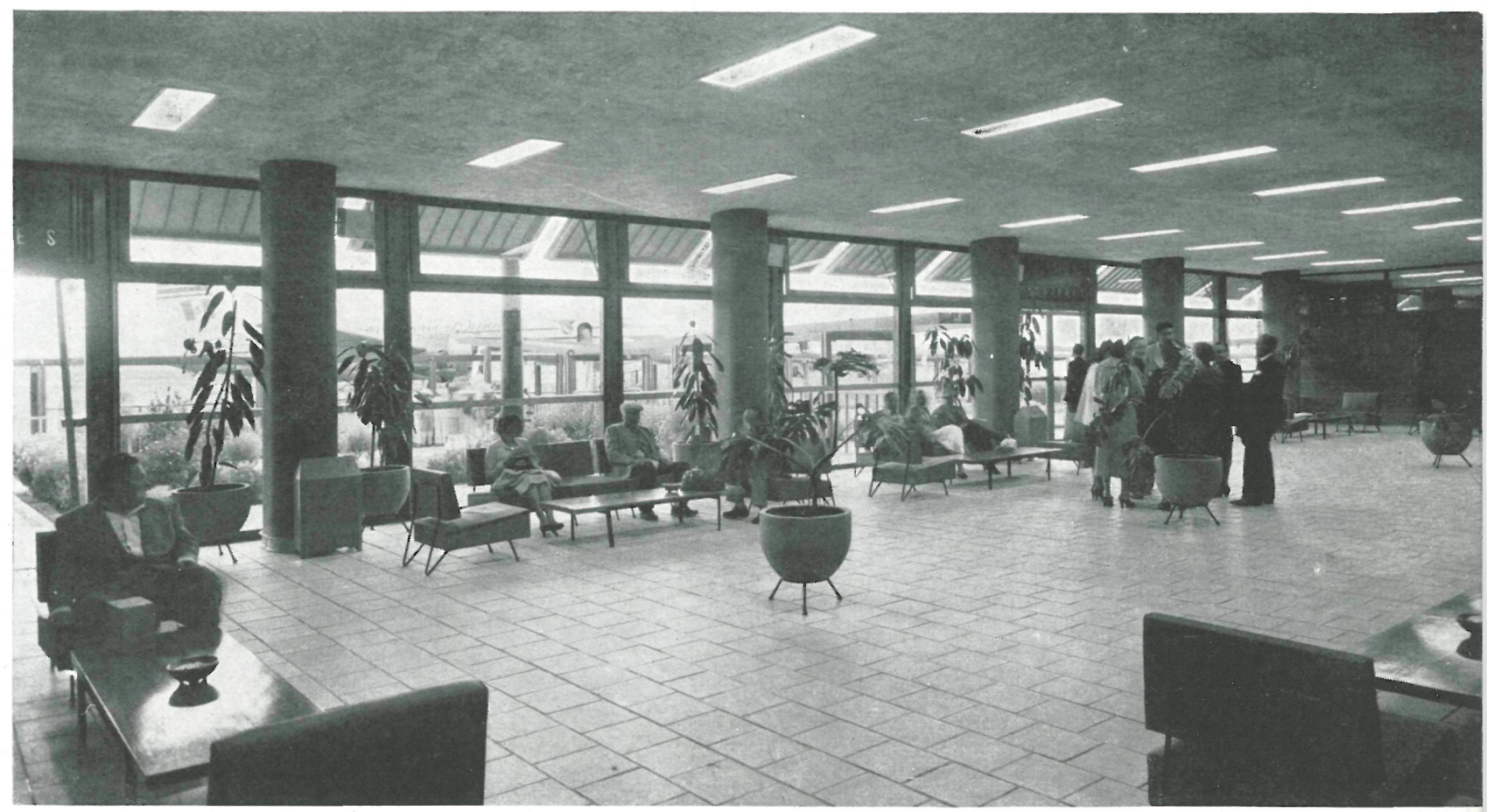

Dos elementos verticales

- la esbelta torre de mando y el edificio de la Dirección de Aeronáutica Civilcompletan el conjunto, contrastando, franca y abiertamente, con la línea baja y horizontal del cuerpo central.

Todos los cerramientos resultan diáfanos y limpios,

acusando la retícula ortogonal de la carpintería metálica.

Placados de piedra y muros ciegos de fábricas de ladrillo rojo alternan en la composición exterior con las grandes superficies acristaladas.

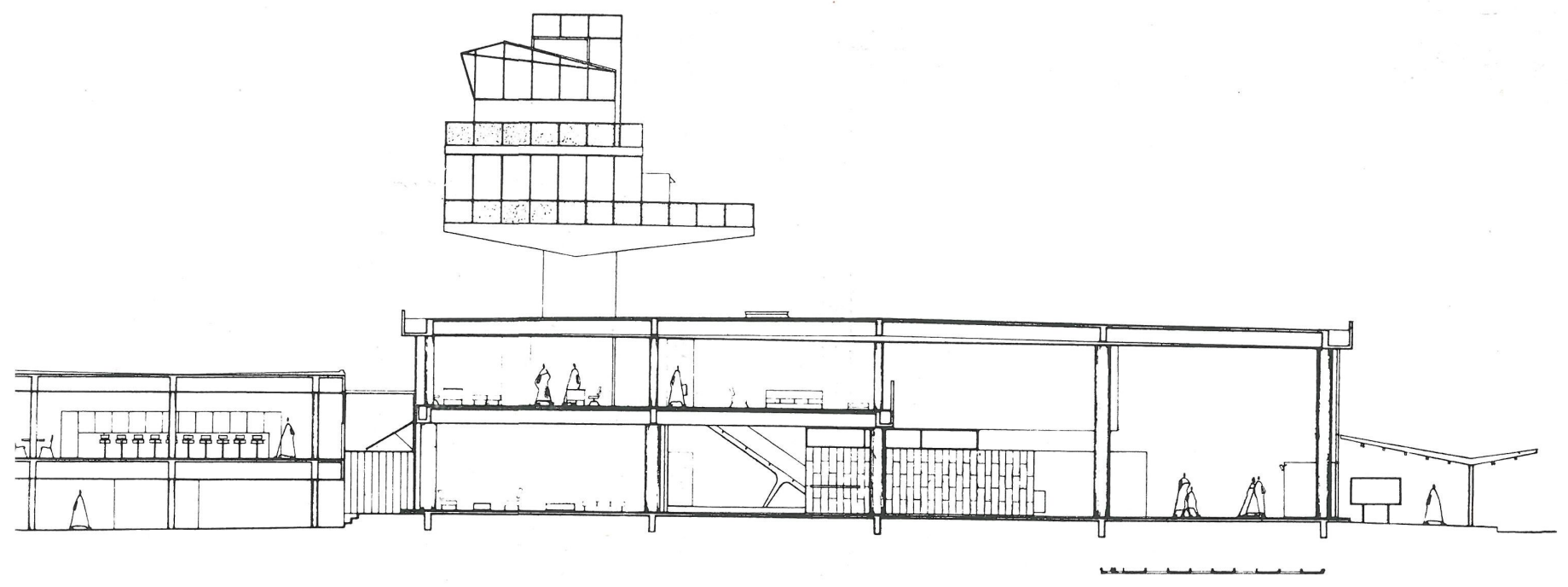




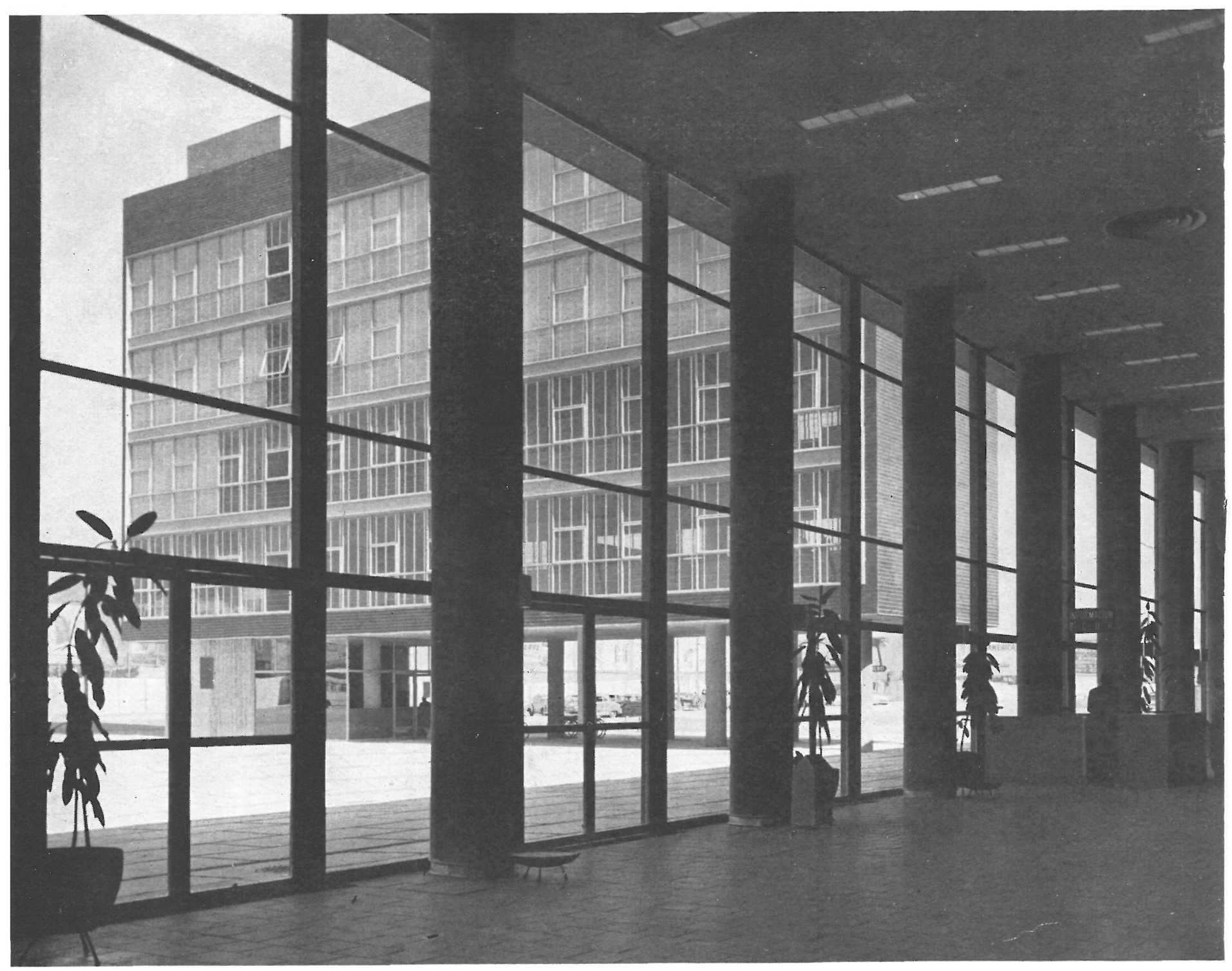

En el interior la decoración es sencilla, viva de colores, y el mobiliario felizmente resuelto con líneas funcionales y modernas.

Arquitectónicamente este edificio constituye una clara muestra del puesto avanzado de la Arquitectura moderna mejicana, que impresiona por su magnitud, funcionalismo y composición, felizmente resuelta en una arquitectura abierta, e íntimamente ligada a las zonas ajardinadas y al siempre atractivo trasiego de las pistas de un aeropuerto. 